\title{
Development and validation of a liquid chromatography-tandem mass spectrometric method for the determination of lenalidomide in human plasma and its application on bioequivalence studies
}

\author{
R. Gopinath', S. T. Narenderan², M. Kumar ${ }^{1}$ and B. Babu ${ }^{2^{*}}$ (D)
}

\begin{abstract}
A simple, sensitive, and specific liquid chromatography-tandem mass spectrophotometry (LC-MS/MS) method was developed and validated for the quantification of lenalidomide in human plasma. The separation was carried out on a symmetry, $\mathrm{C}_{18}, 5-\mu \mathrm{m}(50 \times 4.6 \mathrm{~mm})$ column as stationary phase and with an isocratic mobile phase of $0.1 \%$ formic acid in water-methanol in the ratio of $(15: 85, \mathrm{v} / \mathrm{v})$ at a flow rate of $0.5 \mathrm{~mL} / \mathrm{min}$. Protonated ions formed by electrospray ionization in the positive mode were used to detect analyte and fluconazole (internal standard). The mass detection was made by monitoring the fragmentation of $\mathrm{m} / \mathrm{z} 260.1 / 148.8$ for lenalidomide and $\mathrm{m} / \mathrm{z}$ 307.1/ 238.0 for internal standard on a triple quadrupole mass spectrometer. The developed method was validated over the concentration range of $10-1000 \mathrm{ng} / \mathrm{mL}$ for lenalidomide in human plasma with a correlation coefficient $\left(r^{2}\right)$ was 0.9930. The accuracy and precision values obtained from six different sets of quality control samples analyzed on separate occasions ranged from 99.41 to $106.97 \%$ and 2.88 to $4.22 \%$, respectively. Mean extraction recoveries were $98.06 \%$ and $88.78 \%$ for the analyte and IS, respectively. The developed method was successfully applied for analyzing lenalidomide in human plasma samples.
\end{abstract}

Keywords: Lenalidomide, LC-MS/MS, Human plasma, Electrospray ionization, Pharmacokinetics

\section{Introduction}

Lenalidomide is a derivative of thalidomide; it was initially intended as a treatment for multiple myeloma for which thalidomide is an accepted therapeutic treatment. Lenalidomide has also shown efficacy in the class of hematological disorders known as myelodysplastic syndromes (MDS). Lenalidomide has significantly improved overall survival in myeloma (which generally carries a poor prognosis), although toxicity remains an issue for users (Gupta et al. 2001; Hideshima et al. 2006; McCarthy et al. 2012; Palumbo

\footnotetext{
* Correspondence: babu@jssuni.edu.in

${ }^{2}$ Department of Pharmaceutical Analysis, JSS College of Pharmacy,

Udhagamandalam (Constituent college of JSS Academy of Higher Education

\& Research), The Nilgiris, Tamilnadu 643001, India

Full list of author information is available at the end of the article
}

et al. 2008; Shah Tran 2007; Tariman 2007). Lenalidomide is rapidly absorbed following oral administration. Following single and multiple doses in patients with multiple myeloma or MDS, the maximum plasma concentrations occurred between 0.5 and $6 \mathrm{~h}$ post-dose. The single- and multiple-dose pharmacokinetic disposition of lenalidomide is linear with AUC and $C_{\max }$ values increasing proportionally with dose. Lenalidomide undergoes limited metabolism. Unchanged lenalidomide is the predominant circulating component in humans. It is eliminated primarily in renal, and the mean half-life of lenalidomide is $3 \mathrm{~h}$ in healthy subjects and 3 to $5 \mathrm{~h}$ in patients (MYOPATHY n.d.; Richardson et al. 2002). Few analytical methods have been reported for the estimation of lenalidomide in bulk form and capsule dosage forms (Darwish et al. 2012; Reddy et al. 2012; 


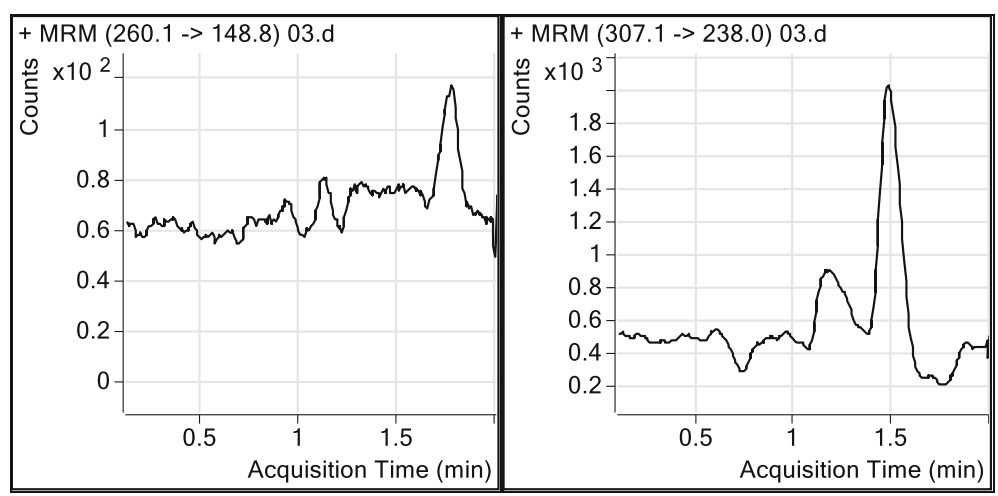

Fig. 1 Representative chromatogram of human blank plasma sample of lenalidomide and IS

Saravanan et al. 2007; Sastry et al. 2009); besides few analytical methods, determination of lenalidomide in human plasma and other biological matrices have been reported (Hasnain et al. 2013; Khalil et al. 2013; Ranganathan et al. 2018; Saha 2019; Veeraraghavan et al. 2014; Veeraraghavan et al. 2015). Some of these reported methods have their individual advantages of short runtime and improved method sensitivity and sample treatment. However, it is essential to have one method which is economical and has significant advantages over a group of methods. Hence, the aim of the present study is to develop an economical, reliable, sensitive, and validated method for the estimation of lenalidomide in human plasma by tandem mass spectrometry using liquid-liquid extraction method.

\section{Experimental}

\section{Chemicals and reagents}

Lenalidomide working standards (99.9\%) were obtained from Vivan Life Sciences Pvt. Ltd. (Mumbai, India), and fluconazole working standards $(98.85 \%)$ were obtained from Tablets India Ltd. (Chennai, India). Methanol (LC-MS CHROMA$\mathrm{SOLV}^{\circ}$ ) and formic acid (LC-MS ultra) were obtained from Sigma Aldrich (St. Louis, MO, USA). Ethyl acetate (HPLC grade) was obtained from Rankem Chemicals (India). All other reagents were of analytical grade unless stated otherwise, and all solutions were prepared using a Milli-Q water purification system from Millipore (Bangalore, India). Blank human plasma ( $\mathrm{K}_{2}$ EDTA as an anticoagulant) was obtained from Sri Venkateshwara Blood Bank, Chennai, India.

\section{Instrument and conditions}

The LC-MS/MS analyses were performed using an Agilent 6460 triple quadrupole LC-MS system (Agilent Technologies, Palo Alto, CA) with a column of Symmetry $\mathrm{C}_{18}(50 \times 4.6 \mathrm{~mm}) 5 \mu \mathrm{m}$ (Waters, USA). The mobile phase was $0.1 \%$ formic acid in water-methanol $(15$ : $85, \mathrm{v} / \mathrm{v}$ ) at a flow rate of $0.5 \mathrm{~mL} / \mathrm{min}$. The column temperature was maintained at $30^{\circ} \mathrm{C}$. A quadrupole mass spectrometer equipped with an electrospray ionization source was set with a capillary voltage $3500 \mathrm{~V}$, Nozzle voltage $1500 \mathrm{~V}$, drying gas $\left(\mathrm{N}_{2}\right)$ flow of $5 \mathrm{~L} / \mathrm{min}$, nebulizer pressure of $25 \mathrm{psi}$, drying gas temperature of $350^{\circ} \mathrm{C}$, sheath gas temperature $300^{\circ} \mathrm{C}$, sheath gas flow 11 $\mathrm{L} / \mathrm{min}$, collision energy 8 and positive ion mode. Quantitation was performed in multiple reaction monitoring modes (MRM) with the transition of parent ions to the product ions $\mathrm{m} / \mathrm{z}$ 260.1/148.8 for lenalidomide and $\mathrm{m} / \mathrm{z}$ 307.1/238.0 for fluconazole; fragment or voltage was $100 \mathrm{~V}$; resolution was maintained at unit resolution, and dwell time was set at $100 \mathrm{~ms}$. System control and data analysis were performed by MassHunter workstation (version B.05.01).

\section{Preparation of calibration standards and quality control samples}

Stock solutions of lenalidomide and fluconazole (IS) were prepared in methanol at a concentration of $1000 \mu \mathrm{g} / \mathrm{mL}$, respectively (Tohnya et al. 2004). A series of lenalidomide working standard solutions in the concentration range of

Table 1 Precision and accuracy results for lenalidomide in human plasma

\begin{tabular}{|c|c|c|c|c|c|c|}
\hline \multirow{2}{*}{$\begin{array}{l}\text { Spiked } \\
\text { conc. } \\
\text { (ng/ } \\
\mathrm{mL} \text { ) }\end{array}$} & \multicolumn{3}{|l|}{ Intra-day } & \multicolumn{3}{|l|}{ Inter-day } \\
\hline & Calculated conc. (mean \pm SD) & Precision (\% CV) & Accuracy (\% RE) & Calculated conc. (mean \pm SD) & Precision (\% CV) & Accuracy (\% RE) \\
\hline 10.00 & $10.76 \pm 0.38$ & 3.51 & -7.58 & $10.60 \pm 0.31$ & 2.88 & -6.01 \\
\hline 26.25 & $28.09 \pm 0.41$ & 1.47 & -7.0 & $28.08 \pm 0.83$ & 2.95 & -6.96 \\
\hline 323.06 & $326.65 \pm 14.93$ & 4.57 & -1.11 & $324.68 \pm 12.76$ & 3.93 & -0.50 \\
\hline 807.64 & $791.12 \pm 20.57$ & 2.60 & 2.05 & $802.87 \pm 33.89$ & 4.22 & 0.59 \\
\hline
\end{tabular}




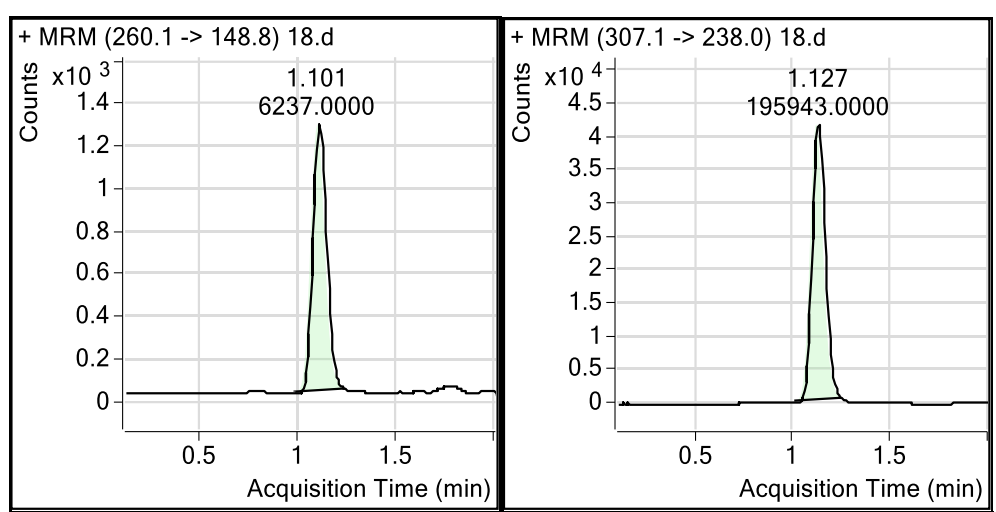

Fig. 2 Representative chromatogram of blank plasma sample spiked with lenalidomide at the LLOQ of $10 \mathrm{ng} / \mathrm{mL}$ and I.S (1000 ng/mL)

$500-50000 \mathrm{ng} / \mathrm{mL}$ were obtained by further diluting the stock solution with $50 \%$ methanol in water solution. The fluconazole working solution of a final concentration of $1000 \mathrm{ng} / \mathrm{mL}$ was obtained by the same method. All solutions were stored at $4{ }^{\circ} \mathrm{C}$ until analysis. The plasma calibration standards of lenalidomide with final concentrations of 10, 25, 50, 150, 300, 500, 700, 900, and $1000 \mathrm{ng} /$ $\mathrm{mL}$ were prepared by spiking a $980 \mu \mathrm{L}$ aliquot of blank plasma with a $20 \mu \mathrm{L}$ aliquot of lenalidomide working standard solutions. Quality control samples (LLOQ, lower limit of quantification; LQC, low-quality control; MQC, middle-quality control; HQC, high-quality control) of 10 , 25,325 , and $800 \mathrm{ng} / \mathrm{mL}$ were prepared in the same way as calibration standards. The bulk samples were aliquoted $(300 \mathrm{~mL})$ into polypropylene tubes and stored at $-80^{\circ} \mathrm{C}$ for further analysis.

\section{Extraction of plasma samples}

An aliquot of $200 \mu \mathrm{L}$ plasma sample and $50 \mu \mathrm{L}$ of IS solution (1000 ng/mL fluconazole) were added into $5 \mathrm{~mL}$ polypropylene tube. Add $50 \mu \mathrm{L}$ of $0.1 \%$ formic acid and vortex and add $2.5 \mathrm{~mL}$ of ethyl acetate, the sample was placed on a platform shaker for $10 \mathrm{~min}$ at $2000 \mathrm{rpm}$, followed by centrifugation at $4000 \mathrm{rpm}$ for $10 \mathrm{~min}$. The organic layer was separated from the aqueous and evaporated to dryness at $50{ }^{\circ} \mathrm{C}$ under a nitrogen stream. The residue was reconstituted in $400 \mu \mathrm{L}$ of the mobile phase, and10 $\mu \mathrm{L}$ was injected for LC-MS/MS for analysis.

\section{Optimization of MS condition}

A standard solution of lenalidomide and fluconazole (IS) was directly infused along with the mobile phase into the mass spectrometer in the ESI source. The mass spectrometer was tuned in positive ionization mode for the optimum response of lenalidomide and fluconazole. In the positive precursor ion full-scan spectra, the most abundant ions were protonated ions $[\mathrm{M}+\mathrm{H}]^{+}, \mathrm{m} / \mathrm{z} 260.1$ and 307.1 for lenalidomide and fluconazole, respectively. Parameters such as gas flow, gas temperature, nebulizer pressure, fragmentation, and capillary voltage were optimized for fine-tuning to obtain the best response. The product ion scan spectra showed high abundance fragment ions at m/z 148.8 for lenalidomide and m/z 238 for fluconazole. The fragmentation voltage and collision energy were optimized for the maximum response of the fragmentation of $\mathrm{m} / \mathrm{z} 148.8$ for lenalidomide and $\mathrm{m} / \mathrm{z}$ 238 for fluconazole. The ion transitions of $\mathrm{m} / \mathrm{z} 260.1 \rightarrow$ 148.8 and $\mathrm{m} / \mathrm{z} 307.1 \rightarrow 238.0$ were chosen for lenalidomide and fluconazole, respectively.

\section{Optimization of LC condition}

The chromatographic conditions were modified to obtain high sensitivity and sample throughput. The separation and ionization of lenalidomide and fluconazole were affected by the composition of the mobile phase. The chromatographic conditions were optimized with different compositions of the mobile phase system using formic acid, ammonium acetate, methanol/acetonitrile being used for the determination. The highest ionization efficiency of lenalidomide and fluconazole was achieved when the ration of $0.1 \%$ formic acid in water and methanol $(15: 85 \mathrm{v} / \mathrm{v})$. The chromatographic column, Agilent Zorbax Eclipse XDB-C18 $(4.6 \times 50 \mathrm{~mm}) 5 \mu \mathrm{m}$, and Symmetry $C_{18}(50 \times 4.6 \mathrm{~mm}) 5 \mu \mathrm{m}$ were investigated in the chromatographic separation. The Symmetry $\mathrm{C}_{18}(50 \times$ $4.6 \mathrm{~mm}) 5 \mu \mathrm{m}$ column was proved to be better than the others, which was tested to achieve shorter run time $(2.0 \mathrm{~min})$, better resolution, and symmetric peak shapes for lenalidomide and fluconazole.

Table 2 Absolute and IS normalized matrix effect of lenalidomide in human plasma

\begin{tabular}{lll}
\hline $\begin{array}{l}\text { Spiked conc. } \\
(\mathrm{ng} / \mathrm{mL})\end{array}$ & $\begin{array}{l}\text { Absolute matrix } \\
\text { factor }\end{array}$ & $\begin{array}{l}\text { IS normalized } \\
\text { matrix factor }\end{array}$ \\
\hline 26.25 & 0.97 & 0.89 \\
807.64 & 1.02 & 0.91 \\
\hline
\end{tabular}




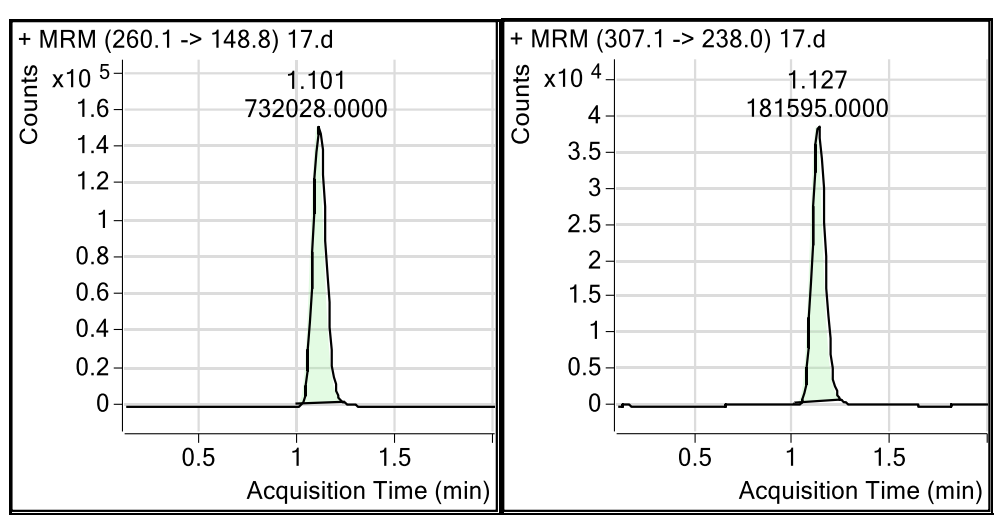

Fig. 3 Representative chromatogram of blank plasma sample spiked with lenalidomide at the HQC of $800 \mathrm{ng} / \mathrm{mL}$ and I.S (1000 ng/mL)

\section{Clinical study design}

Twelve healthy Indian female volunteers participated in the study following Helsinki declaration (Protocol No: 1924 version 1.0 Feb 26 2016). After an overnight fasting, each volunteer received one capsule containing 25 mg lenalidomide, either test or reference formulation. Blood was sampled pre-dose and at 0.25, 0.5, 0.75, 1.0, $1.25,1.50,2.0,2.5,3.0,3.5,4.0,5.0,6.0,7.0,8.0,10.0,12.0$, 16.0 , and $24.0 \mathrm{~h}$ post-dose for the determination of plasma concentration of lenalidomide (Iqbal et al. 2013; Liu et al. 2008).

\section{Pharmacokinetic analysis}

Model-independent pharmacokinetic parameters were calculated for lenalidomide. The maximum plasma concentrations $\left(C_{\max }\right)$ and the time to those $\left(t_{\max }\right)$ were noted directly. The elimination rate constant $\left(k_{\mathrm{el}}\right)$ was calculated by linear regression of the terminal points of the semi-log plot of plasma concentration against time. Elimination half-life $\left(t_{1 / 2}\right)$ was calculated from the formula $t_{1 / 2}=0.693 / k_{\mathrm{el}}$. Area under the plasma concentration-time curve $\left(\mathrm{AUC}_{0-24}\right)$ was calculated by the linear trapezoidal rule.

\section{Results and discussion}

\section{Validation of the method}

Full method validation was performed according to guidelines set by the US Food and Drug Administration (USFDA) (USFDA 2001; Gopinath et al. 2011; Hasnain et al. 2013). Specificity was determined by analyzing six blank human plasma samples without adding an internal standard to determine the interference of the analyte. Matrix effects for lenalidomide were evaluated by comparing the peak areas of analyte in extracted blank plasma samples from six different drug-free volunteers spiked the known concentrations with the corresponding peak areas obtained by direct injection of standard solutions, IS normalized matrix effects were also investigated. Linearity was analyzed by weighted linear regression $\left(1 / X^{2}\right)$ of analyte-internal standard peak area ratios. The calibration curves $(n=8)$ were prepared by spiking blank human plasma with a standard solution of

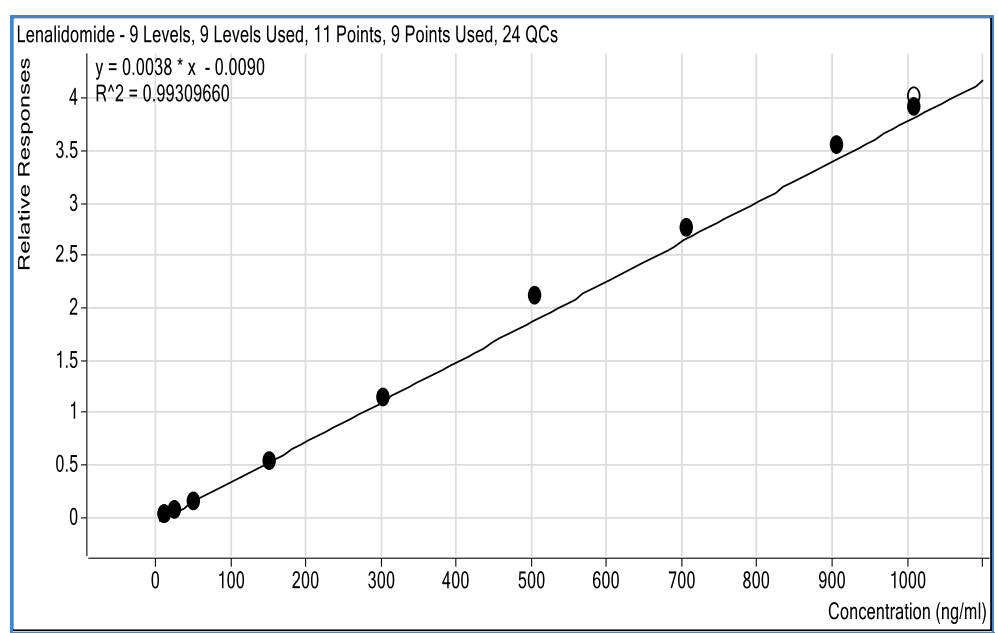

Fig. 4 Representative calibration curve for lenalidomide in matrix 
Table 3 Extraction recoveries of lenalidomide and IS in human plasma

\begin{tabular}{lll}
\hline Spiked conc. $(\mathrm{ng} / \mathrm{mL})$ & Extraction recoveries (\%) & $\% \mathrm{CV}$ \\
\hline 26.25 & 97.32 & 2.15 \\
323.06 & 98.58 & 0.59 \\
807.64 & 98.28 & 2.12 \\
Mean & 98.06 & 1.62 \\
Internal standard & 88.78 & 4.00 \\
\hline
\end{tabular}

lenalidomide. The LLOQ was the smallest analytical concentration at which the precision expressed by the coefficient of variation (CV) was lower than $20 \%$ and the accuracy evaluated by the deviation of the mean from the true value (Dev) was lower than $20 \%$.

Intra-day, inter-day precision and accuracy were determined by analyzing QC samples $(n=6)$ on three different days. The extraction recoveries of lenalidomide were determined by comparing the results obtained from the spiked plasmas to standard solutions. Stability tests including five freeze-thaw cycles, dry extract stability in room temperature, autosampler stability at $4{ }^{\circ} \mathrm{C}$, benchtop stability, and long-term stability in plasma at $-20{ }^{\circ} \mathrm{C}$ and $-80^{\circ} \mathrm{C}$ were evaluated by QC samples at two different concentrations.

\section{Method validation}

\section{Specificity and selectivity}

Specificity and selectivity were evaluated by comparing chromatograms of six blank plasma lots with the spiked plasma to make sure there were no significant interfering peaks at retention time at LLOQ of the analytes. The representative chromatograms are shown in Fig. 1, which indicated that no endogenous interferences were observed at the retention time for lenalidomide and fluconazole. Typical retention times were 1.10 and 1.12 min for lenalidomide and fluconazole, respectively, with a total runtime of 2.0 min (Figs. 2 and 3).

\section{Linearity of calibration curves and lower limits of quantification}

The linearity was determined in the range of 10.0 to 1000.0 $\mathrm{ng} / \mathrm{mL}$ by plotting the peak area ratio $(y)$ of lenalidomide to IS versus the nominal concentration $(x)$ of lenalidomide in plasma. The average regression equation for the calibration curve $(n=9)$ was $y=0.0038 x-0.0090, r^{2}=0.9930$, which is represented in Fig. 4. The slopes of the regression equations were consistent for the calibration curves prepared on five separate days. The LLOQ was set at the level of the lowest calibrators for the analyte $(10 \mathrm{ng} / \mathrm{mL})$ and was evaluated for the other QC samples individually spiked to at least 6 different lots of plasma, with precision and accuracy reported in Table 1 with RE \% within $\pm 20 \%$ and $\%$ CV lower than $20 \%$.

\section{Precision and accuracy}

Validation runs were conducted on three consecutive days. In each run, QC samples were evaluated in sets of six replicates to evaluate the intra-day and inter-day precision and accuracy. The percentage deviation of the

Table 4 Stability of lenalidomide in plasma samples

\begin{tabular}{|c|c|c|c|}
\hline Nominal concentration $(\mathrm{ng} / \mathrm{mL})$ & Obtained concentration (ng/mL) & $\% \mathrm{CV}$ & $\% \mathrm{RE}$ \\
\hline \multicolumn{4}{|l|}{ Autosampler stability } \\
\hline 26.25 & $26.63 \pm 0.89$ & 3.34 & -1.46 \\
\hline 807.64 & $815.27 \pm 29.37$ & 3.6 & -0.94 \\
\hline \multicolumn{4}{|l|}{ Freeze-thaw stability } \\
\hline 26.25 & $27.56 \pm 0.70$ & 2.54 & -4.99 \\
\hline 807.64 & $805.36 \pm 29.96$ & 3.72 & 0.28 \\
\hline \multicolumn{4}{|l|}{ Bench top stability } \\
\hline 26.25 & $27.02 \pm 1.17$ & 4.33 & -2.94 \\
\hline 807.64 & $808.84 \pm 6.81$ & 0.84 & -0.15 \\
\hline \multicolumn{4}{|c|}{ Dry extract stability in room temperature } \\
\hline 26.25 & $26.26 \pm 1.26$ & 4.81 & -0.04 \\
\hline 807.64 & $792.79 \pm 30.55$ & 3.85 & 1.84 \\
\hline \multicolumn{4}{|c|}{ Long term stability in plasma at 65 days in $-80^{\circ} \mathrm{C}$} \\
\hline 26.25 & $25.47 \pm 0.36$ & 1.42 & 2.95 \\
\hline 807.64 & $786.65 \pm 6.01$ & 0.76 & 2.60 \\
\hline \multicolumn{4}{|c|}{ Long term stability in plasma at 65 days in $-20^{\circ} \mathrm{C}$} \\
\hline 26.25 & $25.01 \pm 0.49$ & 1.96 & 4.71 \\
\hline 807.64 & $785.27 \pm 0.82$ & 0.82 & 2.75 \\
\hline
\end{tabular}




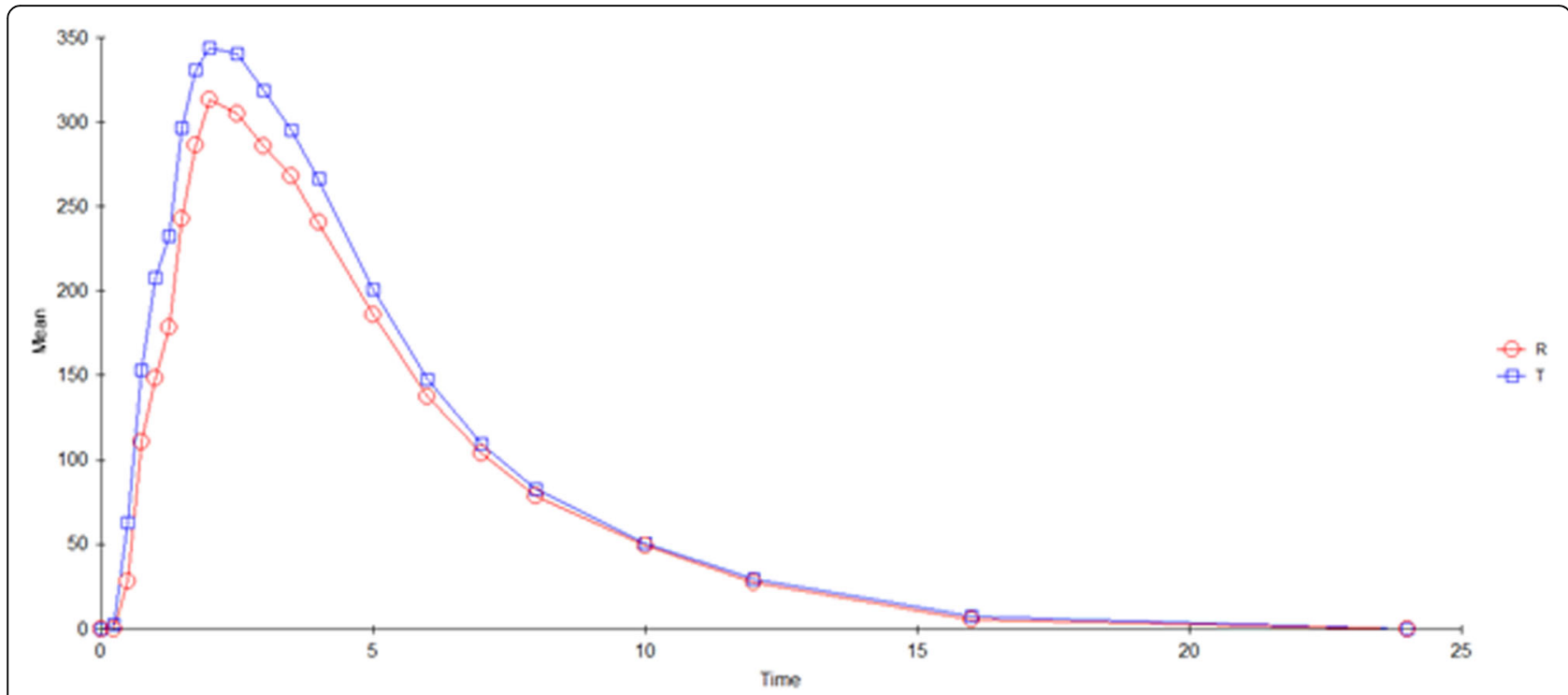

Fig. 5 Mean plasma concentration ( $\mathrm{ng} / \mathrm{mL}$ ) profile of lenalidomide following $25 \mathrm{mg}$ oral dose of test $(\mathrm{T})$ and reference (R) preparation to 12 healthy human volunteers

mean from true values, expressed as a relative error $(\mathrm{RE})$, and the \% CV served as the measure of accuracy and precision, respectively. Summary of precision and accuracy data are presented in Table 1 . The values were all within the acceptable range.

\section{Matrix effect}

The absolute matrix effects for lenalidomide were assessed at low and high concentrations. It was assessed by comparing the mean peak areas of the analyte spiked at two concentrations into the extracts originated from six different blank human plasma samples the mean peak areas for neat solutions of the analytes in 50\% methanol in water. Summary of matrix effect data are presented in Table 2 and shown in Figs. 2 and 3. It is demonstrated that the matrix effect was not independent of the concentration.

\section{Extraction recovery}

Ethyl acetate was chosen as the extraction solvent for its higher extraction efficiency to the two target compounds.
The extraction recoveries of lenalidomide and fluconazole can be promoted by acidifying the plasma samples with formic acid, so $50 \mu \mathrm{L}$ of $0.1 \%$ formic acid was added to $200 \mu \mathrm{L}$ of plasma sample before extraction. Recovery was calculated by comparison of the peak areas of lenalidomide extracted from plasma samples with those of injected standards. The mean recovery of lenalidomide and IS from human plasma with ethyl acetate was $98.06 \pm$ $1.62 \%$ and $88.78 \pm 4.0 \%$. The results are shown in Table 3 .

\section{Stability}

QC samples (LQC and HQC) of six replicates were subjected to the conditions below. Autosampler stability was assessed by analyzing processed QC samples kept in the autosampler at $4{ }^{\circ} \mathrm{C}$ for $47 \mathrm{~h} 33 \mathrm{~min}$ to evaluate post-preparative stability, with -1.46 and $-0.94 \%$ and precision of 3.34 and $3.60 \%$. Freeze-thaw stability was investigated after five freeze-thaw cycles $\left(-80{ }^{\circ} \mathrm{C}\right)$, with $\mathrm{RE}$ of -4.99 and $0.28 \%$ and precision (\% CV) of 2.54 and $3.72 \%$. Bench stability was assessed by analyzing QC plasma samples kept at room temperature for $15 \mathrm{~h} 45 \mathrm{~min}$ which exceeded the routine preparation time of samples, with RE of -2.94 and $-0.15 \%$ and precision of 4.33

Table 5 Mean pharmacokinetic parameters of lenalidomide in 12 human volunteers

\begin{tabular}{llr}
\hline Parameters & Reference (mean \pm SD) & Test (mean \pm SD) \\
\hline$C_{\max }(\mathrm{h})$ & $338.73 \pm 87.44$ & $390.50 \pm 144.47$ \\
$A \cup C_{0-\mathrm{t}}(\mathrm{ng} . \mathrm{h} / \mathrm{mL})$ & $1669.63 \pm 620.29$ & $1883.66 \pm 757.12$ \\
$\mathrm{~A} \cup C_{0-\infty}(\mathrm{ng} . \mathrm{h} / \mathrm{mL})$ & $1792.35 \pm 681.77$ & $1982.24 \pm 791.43$ \\
$t_{\max }(\mathrm{h})$ & $2.03 \pm 0.70$ & $2.08 \pm 0.61$ \\
$k_{\mathrm{el}}$ & $0.26 \pm 0.05$ & $0.26 \pm 0.05$ \\
$t_{1 / 2}(\mathrm{~h})$ & $2.80 \pm 0.64$ & $2.79 \pm 0.58$ \\
\hline
\end{tabular}


and $0.84 \%$. Dry extract stability was assessed by analyzing extracted QC plasma samples (without reconstitution) kept at room temperature for $69 \mathrm{~h} 25 \mathrm{~min}$, with $\mathrm{RE}$ of -2.94 and $0.15 \%$ and precision of 4.33 and $0.84 \%$.

Long-term stability was determined by assaying QC samples after storage at $-80{ }^{\circ} \mathrm{C}$ and $-20^{\circ} \mathrm{C}$ for 65 days, with $\mathrm{RE}$ of 2.95 and $2.60 \%$ and precision of 1.42 and $0.76 \%$ for LQC and HQC samples at $-80{ }^{\circ} \mathrm{C}$, with RE of 4.71 and $2.75 \%$ and precision of 1.96 and $0.82 \%$ for LQC and HQC samples at $-20^{\circ} \mathrm{C}$. The stock solutions' stability was investigated at mid-quality control sample levels $\left(323.06 \mathrm{ng} / \mathrm{mL}\right.$ ) after storage at $4{ }^{\circ} \mathrm{C}$ for 20 days. The results were obtained by a comparison with freshly prepared solutions, lenalidomide, and IS stock solutions was stable at refrigerated condition. Lenalidomide proved to be stable under all testing conditions. No significant degradation of lenalidomide was observed under any of these conditions. Results are summarized in Table 4.

\section{Application}

The method described above was successfully applied to the bioequivalence study to determine the plasma concentration of lenalidomide up to $24 \mathrm{~h}$ after an oral administration of the reference and the test formulations of lenalidomide to 12 healthy Indian female volunteers. This study was approved by the Madras ethical committee, Chennai, India. All volunteers gave their signed informed consent to participate in the study according to the principles of the Declaration of Helsinki. The mean plasma concentration-time curve of lenalidomide is shown in Fig. 5. The mean pharmacokinetic parameters of lenalidomide in 12 volunteers were calculated and summarized in Table 5. Both the mean values and standard deviations of the main pharmacokinetic parameters such as $C_{\max }, t_{\max }, \mathrm{AUC}_{0-24}$, and $\mathrm{AUC}_{0-\infty}$ were found to be close, between test and reference preparations, indicating that plasma profiles generated by test preparations were comparable with those produced by reference preparations. In addition, the calculated 90\% CIs for mean $C_{\max }, \mathrm{AUC}_{\text {last }}$, and $\mathrm{AUCO}_{-\infty}$ of two drugs lay within the FDA's accepted range of $80-125 \%$. Therefore, it could be concluded that the two lenalidomide preparations (test and reference) analyzed were bioequivalent in terms of rate and extent of absorption.

\section{Conclusion}

The above-developed method achieved good sensitivity and specificity for the determination of lenalidomide in human plasma. No significant interferences and matrix effect caused by endogenous compounds were observed. This simple and sensitive assay is suitable for bioequivalence and bioavailability studies of lenalidomide in human subjects. The characteristics of this analytical method are suitable for the routine analysis in a clinical laboratory for pharmacokinetic and bioequivalence studies in humans in a single analytical run.

\section{Abbreviations \\ AUC: Area under a curve; $C_{\max }$ : Maximum concentration; CV: Coefficient of variance; HQC: High-quality control; IS: Internal standard; $k_{\mathrm{e}}$ : Elimination rate constant; LC-MS/MS: Liquid chromatography-tandem mass spectrophotom- etry; LLOQ: Lower limit of quantification; LOQ: Limit of quantification; LQC: Low-quality control; MDS: Myelodysplastic syndromes; MQC: Middle- quality control; MRM: Multiple reaction monitoring; QC: Quality control; RE: Relative error; $t_{1 / 2}$ : Half-life; $t_{\max }$ : Maximum time; USFDA: US Food and Drug Administration}

\section{Acknowledgement}

Not applicable.

\section{Authors' contributions}

All the authors have contributed equally to this research work. All authors read and approved the final manuscript.

\section{Funding}

This research did not receive any specific grant from funding agencies in the public, commercial, or not-for-profit sectors.

\section{Availability of data and materials}

Not applicable.

\section{Competing interests}

The authors declare that they have no competing interests.

\section{Author details}

${ }^{1}$ Faculty of Pharmacy, Vinayaka Mission's Research Foundation (Deemed to be university), Salem, Tamilnadu 636308, India. ${ }^{2}$ Department of Pharmaceutical Analysis, JSS College of Pharmacy, Udhagamandalam (Constituent college of JSS Academy of Higher Education \& Research), The Nilgiris, Tamilnadu 643001, India.

Received: 21 August 2019 Accepted: 31 October 2019

Published online: 28 November 2019

\section{References}

Darwish IA, Khalil NY, Bakheit AH, Alzoman NZ. A highly sensitive fluorimetric method for determination of lenalidomide in its bulk form and capsules via derivatization with fluorescamine. Chem Central J. 2012;6:118.

Gopinath S, S Kumar R, Alexander S, Danabal P. Development and validation of a rapid and sensitive assay for simultaneous quantification of lenalidomide and dexamethasone in human plasma by liquid chromatography coupled to tandem mass-spectrometry. Curr Pharm Analysis. 2011;7:240-7.

Gupta D, Treon S, Shima Y, Hideshima T, Podar K, Tai Y, Lin B, Lentzsch S, Davies $F$, Chauhan D. Adherence of multiple myeloma cells to bone marrow stromal cells upregulates vascular endothelial growth factor secretion: therapeutic applications. Leukemia. 2001;15:1950.

Hasnain MS, Rao S, Singh MK, Vig N, Gupta A, Ansari A, Sen P, Joshi P, Ansari SA. Development and validation of LC-MS/MS method for the quantitation of lenalidomide in human plasma using Box-Behnken experimental design. Analyst. 2013;138:1581-8.

Hideshima T, Richardson PG, Anderson KC. Current therapeutic uses of lenalidomide in multiple myeloma. Expert opinion on investigational drugs. 2006;15:171-9.

Iabal M, Wani TA, Khalil NY, Darwish IA. Development and validation of ultraperformance liquid chromatographic method with tandem mass spectrometry for determination of lenalidomide in rabbit and human plasma. Chem Central J. 2013;7:7.

Khalil NY, Darwish IA, Wani TA, Al-Majed A-RA. Trace determination of lenalidomide in plasma by non-extractive HPLC procedures with fluorescence detection after pre-column derivatization with fluorescamine. Chem Central J. 2013;7:52.

Liu Q, Farley KL, Johnson AJ, Muthusamy N, Hofmeister CC, Blum KA, Schaaf LJ, Grever MR, Byrd JC, Dalton JT. Development and validation of a highly sensitive liquid chromatography/mass spectrometry method for 
simultaneous quantification of lenalidomide and flavopiridol in human plasma. Ther Drug Monit. 2008:30:620.

McCarthy PL, Owzar K, Hofmeister CC, Hurd DD, Hassoun H, Richardson PG, Giralt S, Stadtmauer EA, Weisdorf DJ, Vij R. Lenalidomide after stem-cell transplantation for multiple myeloma. N E J Med. 2012;366:1770-81. MYOPATHY LA. (n.d.) HIGHLIGHTS OF PRESCRIBING INFORMATION.

Palumbo A, San Miguel J, Sonneveld P, Moreau P, Drach J, Morgan G, Einsele H. Lenalidomide: a new therapy for multiple myeloma. Cancer Treat Rev. 2008; 34:283-91.

Ranganathan P, Gunasekaran V, Singhvi I, Ansari MJ. Development and validation of lenalidomide in human plasma by LC-MS/MS. Saudi Journal of Biological Sciences. 2018.

Reddy LM, Reddy KJ, Reddy LB, Reddy PR. Development of a rapid and sensitive HPLC assay method for lenalidomide capsules and its related substances. J Chem. 2012:9:1165-74.

Richardson PG, Schlossman RL, Weller E, Hideshima T, Mitsiades C, Davies F, LeBlanc R, Catley LP, Doss D, Kelly K. Immunomodulatory drug CC-5013 overcomes drug resistance and is well tolerated in patients with relapsed multiple myeloma. Blood. 2002;100:3063-7.

Saha A. (2019) Bioequivalence studies of lenalidomide capsule under fasting and fed conditions in Indian volunteers: application of an advanced UPLC-MS/MS method.

Saravanan G, Rao B, Ravikumar M, Suryanarayana M, Someswararao N, Acharyulu P. Development of an HPLC assay method for lenalidomide. Chromatographia. 2007;66:287-90.

Sastry B, Gananadhamu S, Prasad S, Venu G. New spectrophotometric methods for estimation of lenalidomide in pharmaceutical formulations. Int J PharmTech Res. 2009;1:416-9.

Shah SR, Tran TM. Lenalidomide in myelodysplastic syndrome and multiple myeloma. Drugs. 2007;67:1869-81.

Tariman JD. Lenalidomide: a new agent for patients with relapsed or refractory multiple myeloma. Clin J Oncol Nurs. 2007;11:569.

Tohnya TM, Hwang K, Lepper ER, Fine HA, Dahut WL, Venitz J, Sparreboom A, Figg WD. Determination of CC-5013, an analogue of thalidomide, in human plasma by liquid chromatography-mass spectrometry. J Chromatography B. 2004;811:135-41.

USFDA. Guidance for industry, bioanalytical method validation. http://www.fda. gov/cder/guidance/index.htm. 2001

Veeraraghavan S, Thappali S, Viswanadha S, Nalla S, Chennupati S, Golla M, Vakkalanka S, Rangasamy M. Simultaneous quantification of idelalisib, fludarabine and lenalidomide in rat plasma by using high-performance liquid chromatography coupled with heated electrospray ionization tandem mass spectrometry. J Chromatography B. 2014;949:63-9.

Veeraraghavan S, Viswanadha S, Thappali S, Govindarajulu B, Vakkalanka S, Rangasamy M. Simultaneous quantification of lenalidomide, ibrutinib and its active metabolite PCI-45227 in rat plasma by LC-MS/MS: application to a pharmacokinetic study. Journal of pharmaceutical and biomedical analysis. 2015;107:151-8.

\section{Publisher's Note}

Springer Nature remains neutral with regard to jurisdictional claims in published maps and institutional affiliations.

\section{Submit your manuscript to a SpringerOpen ${ }^{\circ}$ journal and benefit from:}

- Convenient online submission

- Rigorous peer review

- Open access: articles freely available online

- High visibility within the field

- Retaining the copyright to your article

Submit your next manuscript at $\boldsymbol{\nabla}$ springeropen.com 